\title{
LASER TECHNOLOGIES IN ORTHODONTIC PRACTICE - ACHIEVEMENTS AND PROSPECTS
}

\author{
Olena Savchenko \\ Corresponding member of the Ukrainian Academy of Sciences \\ savchenko@mail.ua
}

Introduction. In case of orthopedic restoration, frequency of dental hyperesthesia ranges from $15.0 \%$ to $90.0 \%$ as a result of the fact that preparation of the hard tissues in teeth requires significant polishing. In particular, there is a 41.0-65.0\% increase in tooth sensitivity to thermal, tactile, and chemical stimuli after this procedure. At the same time, disregard of this problem leads to the development of complications, including inflammatory complications [1].

It should be noted that at the moment, we have a large arsenal of pharmacological products that are used for treating dental hyperesthesia. In addition to the therapeutic effect, these products have a negative effect on the patient's body, often causing allergic reactions and other manifestations.

On the contrary, the use of non-drug methods, in particular lasers, in orthodontic practice contributes to the optimal treatment of tooth surface due to high penetrating effect of laser radiation [4]. Low-level laser radiation has an effect on physiological processes on the body level. Mechanism of therapeutic effect of low-level laser radiation on different levels of the organization of biological systems can be represented in the following way: 1) on an atomic-molecular level - absorption of light by a photoacceptor, an external photoelectric effect and an internal photoelectric effect; 2) a unique ability of laser light to restore genetic and membrane system of cells, to reduce the intensity of lipid peroxidation, providing antioxidant and protective effect, is carried into effect on a cellular level $[7,8]$.

Anti-inflammatory, anti-edema, fibrinolytic, thrombolytic, analgesic, desensitizing, and other effects are also clinically significant [6].

It should be taken into account that the mechanism of interaction of highintensity laser radiation with tissues depends on the type and condition of body tissues, their density, composition, water absorption degree, state of the surface (color, smoothness), thermal conductivity, heat capacity, acoustic, mechanical, physical and chemical properties, microstructure (heterogeneity and homogeneity) and others [5].

In addition, the degree of light absorption by tissues is determined by the 
wavelength. Every type of laser is intended for a particular chromophore, laser energy is calibrated taking into account chromophore properties and the intended use of a particular laser.

In particular, a diode laser with a wavelength of $810 \mathrm{~nm}$ allows one to achieve maximum possible absorption of laser energy by enamel tissues, while the coefficient of laser energy absorption remains quite high. Optical fiber allows one to easily get to hard-to-reach areas even in teeth with a pronounced bend. Energy parameters and radiation mode depend on a number of physical characteristics. The range of the use of lasers in dentistry is constantly expanding [2].

Despite the fact that in literature there is enough data on the effectiveness of laser radiation, its practical use in orthodontic practice is very limited. Also, taking into account the above, the effect of laser radiation on different tissues (enamel, dentin, pulp, etc.) differs, so this aspect requires careful and step-bystep development.

The aim of this study was to evaluate the effectiveness of orthodontic treatment with the use of a diode laser device modified by the intensity of laser radiation.

The object and methods of research. The study included 43 patients aged 22-42 (mean age - 29.4 \pm 5.83 years) with displaced first premolars with their concurrent hypersensitivity. In group $1(\mathrm{n}=23)$, hypersensitivity of first premolars was treated using a standard anti-inflammatory therapy with ibuprofen $200 \mathrm{mg}$ twice a day. Group 2 consisted of 20 patients whose hypersensitivity was treated using own modified diode laser device ("A laser device for the use in dentistry for orthodontic treatment") with a wavelength of $810 \mathrm{~nm}$. The procedure was performed using a variable non-initiated optical fiber at a power of $0.5 \mathrm{~W}$ during 1 minute, using both direct contact and movement of the head along a certain trajectory. In group 2 patients were treated during 3 visits at an interval of 1-2 days. Gender and age differences between the groups were unreliable.

Clinical examination of patients was carried out according to a standard protocol, all the information was entered into dental records.

Pain sensations were analyzed according to the visual analog scale (VAS). Patients were asked to evaluate pain they felt in each tooth which was caused by a 5 -second airflow at a distance of $2.5 \mathrm{~cm}$ from a tooth using a 10-point visual analog scale. The first point of the line corresponds to the absence of pain - 0 , followed by weak, moderate, severe, and unbearable pain - 10 . 
Distance between the first point and the point where a mark is made was measured in millimeters.

In order to assess temperature sensitivity of hard dental tissues, an air stream from a dental chip blower was used.

Hygienic and periodontal indices were also calculated. In particular, PMA (papillary-marginal-alveolar) index suggested by Masser and PFRI index for the quantitative evaluation of the rate of dental plaque formation.

Severity of dental hard tissues hyperesthesia was assessed before and after treatment, on the 1st, 3rd and 7th day, which allowed us to determine the intensity of tooth sensitivity before treatment and to analyze clinical effectiveness of the recommended methods.

Statistical analysis was carried out in accordance with the recommendations for processing the results of medical and biological studies [3]. The following software package was used: Statistica for Windows 8.0 (StatSoft, Inc, 2001). Quantitative data was presented as $\mathrm{M} \pm \mathrm{m}$ (mean value \pm standard deviation). At $\mathrm{p}<0.05$, the results were considered to be statistically reliable.

Results of the study and their discussion. According to the results of the study, it was found that according to VAS, pain sensitivity was $7.9 \pm 3.9$ and $8.3 \pm 4.1$ in the study groups. At the end of the course of treatment, it was 2.2 \pm 0.9 (2.59 times reduction of pain sensations) and $1.9 \pm 0.7$ points (3.37 times reduction of VAS parameters), respectively (Fig. 1).

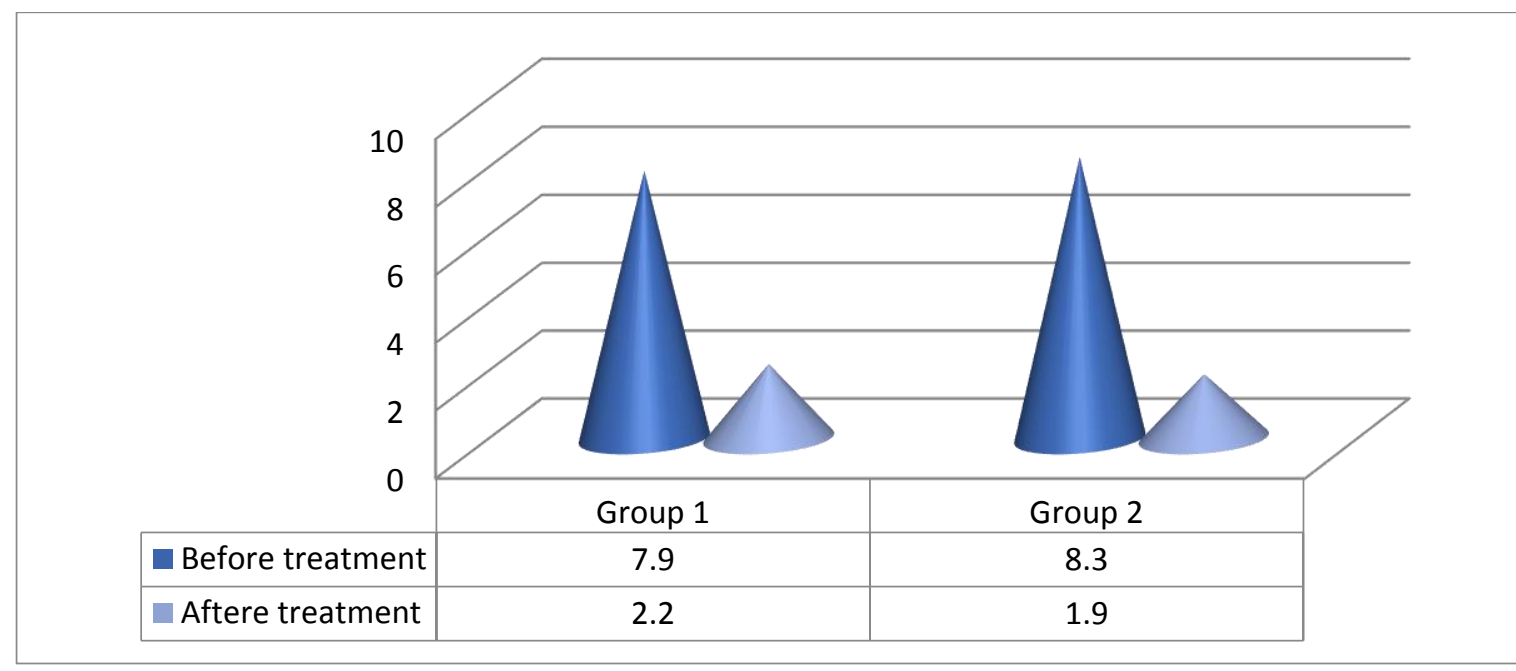




\section{course of treatment.}

Note:

- probability of difference in values in the course of treatment $(\mathrm{p}<0.05)$

That is, there was a reduction in pain in both groups where standard drug therapy and diode laser radiation were used.

On the contrary, treatment of temperature sensitivity was more effective in case of the use of diode laser radiation, which is shown in Figure 2.

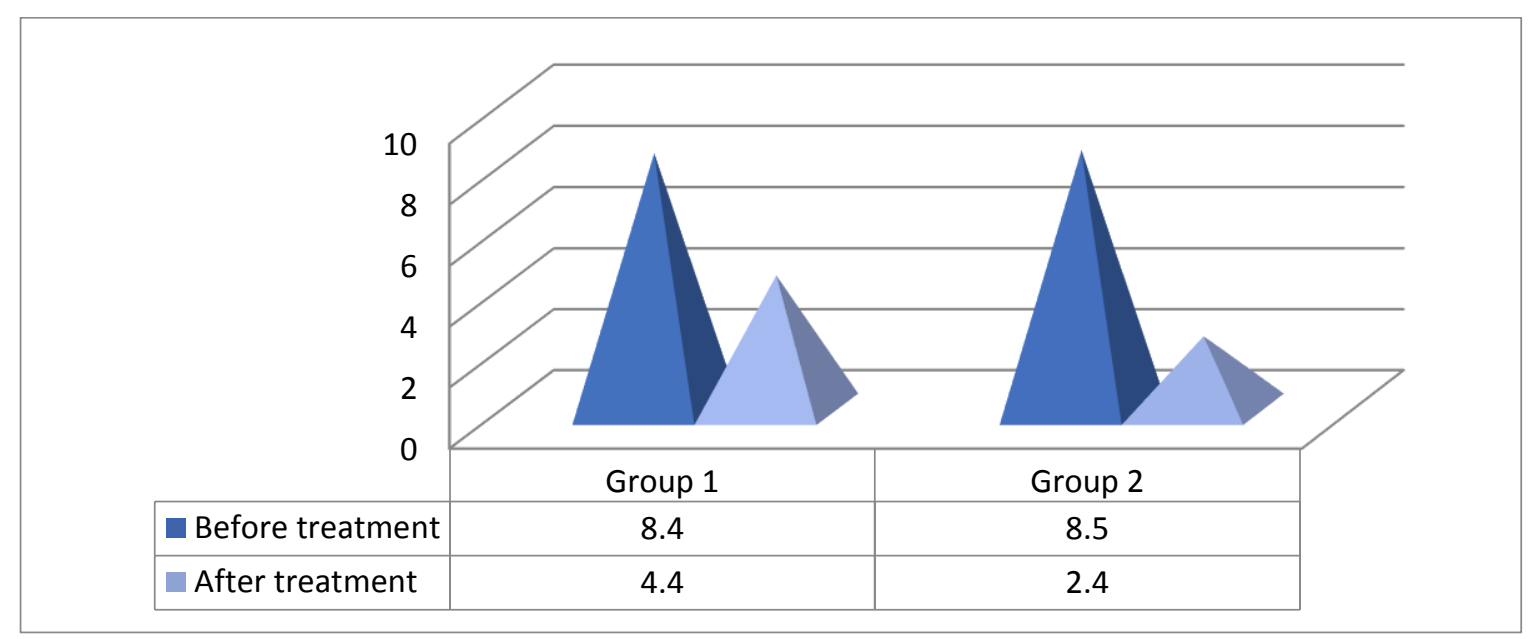

Fig. 2. Temperature sensitivity on a visual analogue scale in the dynamics of treatment.

Note:

t - probability of difference in values in the course of treatment $(\mathrm{p}<0.05)$

As for the analysis of absolute effectiveness, $73.9 \%$ (17.0 people) of patients showed a decrease in temperature sensitivity after laser therapy compared with the absolute effectiveness of anti-inflammatory therapy, which was $40.0 \%$ (8.0 people), probable indicators of relative effectiveness and odds ratios (Table 1). 
Table 1

Absolute effectiveness of anti-inflammatory therapy and laser radiation in patients with teeth hypersensitivity during orthodontic treatment

\begin{tabular}{|c|c|c|c|}
\hline & AE,\% & $\begin{array}{c}\text { RE } \\
{[\mathbf{9 5 \%} \text { ДІ }]}\end{array}$ & OR \\
\hline Group 1 & $40,0 \%$ & 0,54 & 0,24 \\
Group 2 & $73,9 \%$ & {$[0,30-0,98]$} & {$[0,06-0,86]$} \\
\hline
\end{tabular}

Note: $\mathrm{AE}$ - absolute effect;

$$
\begin{aligned}
& \mathrm{RR} \text { - relastive effect; } \\
& \mathrm{OR} \text { - odds ratio. }
\end{aligned}
$$

Changes in periodontal indices at different treatment stages in case of the use of anti-inflammatory therapy in comparison with diode laser therapy are shown in figure 3.

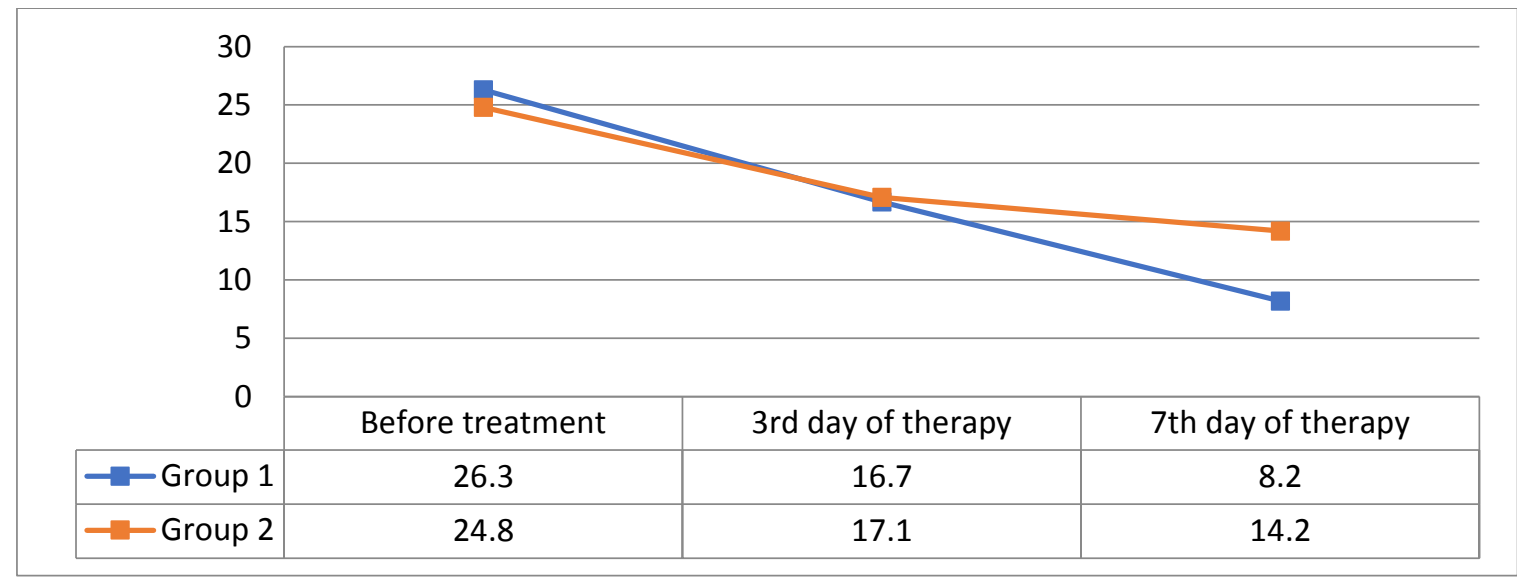

Fig. 3. Changes in the PMA periodontal index in the study groups.

By and large, we can see a decrease in the PMA index in both groups (from $26.3 \pm$ 6.8 to $8.2 \pm 1.91$ in group $1(p<0.05)$ and from $24.8 \pm 5.9$ to $14.2 \pm 3.51(p<0.05)$ in group 2). At the same time, the reduction of PMA index in the non-drug therapy group was more significant $(\mathrm{p} 1<0.05)$. Perhaps this is caused by the comprehensive effect of laser therapy - bactericidal and anti-inflammatory - in comparison with the narrow effect of anti-inflammatory therapy with the use of ibuprofen. 
On the basis of this fact, it is probably also possible to explain changes in the PFRI index for the quantitative evaluation of the rate of dental plaque formation. The obtained data are shown in figure 4.

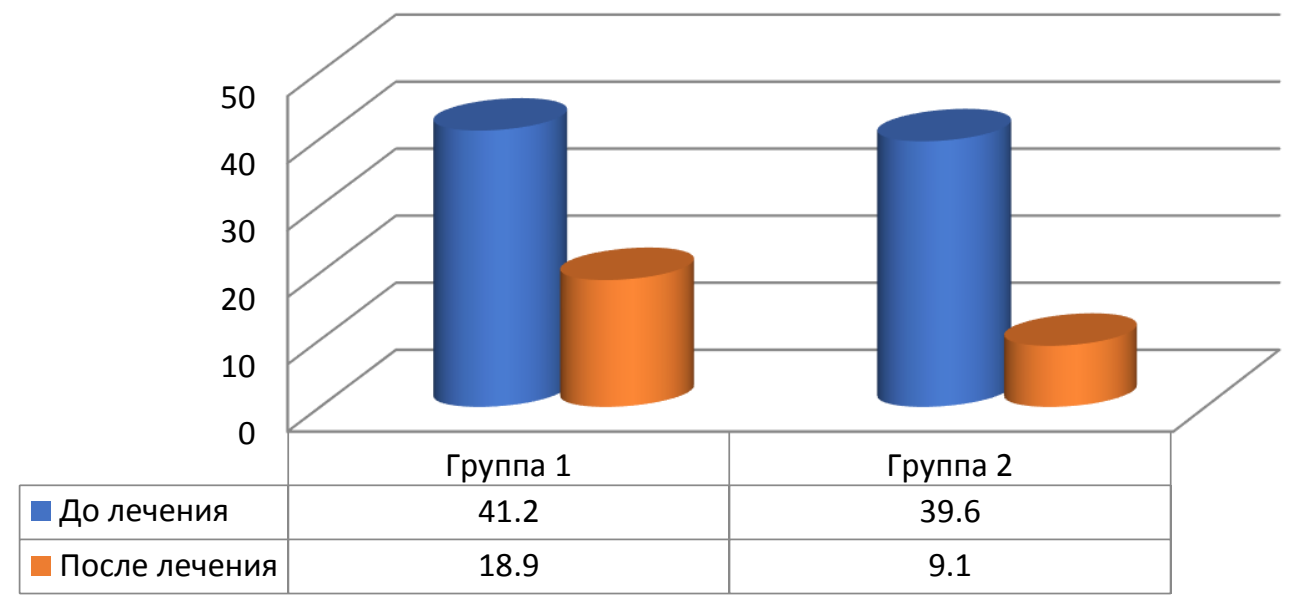

Fig. 4. Changes in the PFRI index in the groups in the course of treatment.

As we can see by the PFRI index, hygienic state of the oral cavity worsened in both groups $(p<0.05)$, with additional probable reduction $(9.1 \pm 3.4$ versus $18.9 \pm$ 4.9 , that is, by additional 9.8 points) in the group where laser therapy was introduced.

The next task of our study was to evaluate frequency of side effects in patients who were prescribed standard drug therapy with ibuprofen versus group 2, where a "Laser device for the use in dentistry for orthodontic treatment" was used.

The following parameters were analyzed: frequency of discomfort in the epigastrium and frequency of increase in alanine aminotransferase (ALT). Frequency of adverse events was assessed taking into account absolute risk $(A R, \%)$ and relative risk (RR).

In particular, 4 patients in group 1, where ibuprofen was prescribed (AR - 10.0\%), complained of discomfort in the epigastrium, whereas none of patients in group 2 , where therapy with the use of diode laser radiation was performed, complained of this. That is, dyspepsia syndrome occurred more frequently when drug therapy was used (Table 2). On the contrary, during laser therapy, patients 
only experienced slight tingling in the exposed area and noted the short duration of treatment. There were also a number of patients with elevated alanine aminotransferase level in case of ibuprofen therapy (10.0\%, 2.0 people), although there was no such side effect in group 2.

Table 2. Probability of discomfort in the epigastrium and increase in transaminases in patients with dental hyperesthesia during orthodontic treatment and various methods of analgesia

\begin{tabular}{|r|c|c|}
\hline & $\mathrm{AR}_{\text {disco }}$ & $\mathrm{AR}_{\mathrm{A}}$ \\
\hline Ibuprofen & $19.0 \%$ & $\begin{array}{c}10.0 \\
\%\end{array}$ \\
\hline $\begin{array}{r}\text { Diode laser } \\
\text { therapy }\end{array}$ & $0.0 \%$ & $0.0 \%$ \\
\hline
\end{tabular}

That is, when assessing overall tolerance of drug therapy with ibuprofen and nondrug therapy with diode laser radiation, $71.0 \%$ and $100.0 \%$ of patients respectively stated that they tolerated treatment well and there were no side effects.

Conclusions

1. According to a visual analog scale, the use of standard anti-inflammatory and diode laser radiation contributes to a probable decrease in pain, however, treatment of temperature sensitivity was more effective in case of the use of diode laser radiation.

2. Based on subjective complaints made by patients with teeth hypersensitivity, absolute effectiveness during orthodontic treatment with the use of one laser radiation is higher compared to drug therapy $(73,9 \%$ versus $40.0 \%)$, relative effectiveness and odds ratio are probable.

3. A probable decrease in the periodontal index in both study groups was confirmed, although PMA index reduction in the non-drug therapy group was higher $(p<0.05)$.

4. Diode laser therapy is highly effective for the hygienic state of the oral cavity, based on the PFRI index with an additional probable reduction by 9.8 points in comparison with anti-inflammatory therapy.

5. Side effects of anti-inflammatory therapy during orthodontic treatment include discomfort in the epigastrium (19.0\%) and increase in liver transaminases (10.0\%), whereas no side effects are observed during laser therapy. 
6. It was proven that diode laser radiation is better tolerated $(100.0 \%)$ in comparison with drug therapy with ibuprofen $(71.0 \%)$ during orthodontic treatment of patients with dental hypersensitivity.

Prospects of further research. The use of laser technologies in orthodontic practice is an effective alternative to drug therapy. Prospects of further research include further modification of the "Laser device for the use in dentistry for orthodontic treatment", testing of different radiation modes for the purpose of achieving analgesic, antibacterial, and regenerative effect, as well as the development and implementation of effectiveness standards for different modes.

\section{Literary sources}

1. Dimitrova Yu.V. Metodyi profilaktiki giperestezii zubov pri protezirovanii nes'emnyimi ortopedicheskimi konstruktsiyami / Yu.V. Dimitrova // Uralskiy med. zhurn. - 2013. - № 1 (93). - S. 58-63.

2. Kiselnikova L.P. Opyit ispolzovaniya diodnogo lazera pri lechenii hronicheskogo pulpita vo vremennyih zubah / L.P. Kiselnikova, A.P. Petrosyan // Endodontiya. - 2012. - № 1. - S. 46-51.

3. Rebrova O.Yu. Statisticheskiy analiz meditsinskih dannyih. Primenenie paketa prikladnyih programm STATISTICA / O.Yu. Rebernaya. - M.: Mediasfera, 2004. $-312 \mathrm{~s}$.

4. Effects of pre-surgical nasoalveolar moulding on maxillary arch and nasal form in unilateral cleft lip and palate before lip surgery /

T. Fuchigami, N. Kimura, T. Kibe [et al.] // Orthod. Craniofac. Res. - 2017. - Vol. 20 (4). - P. 209-215.

5. Farsaii A. Insufficient Evidence Supports the Use of Low-Level Laser Therapy to Accelerate Tooth Movement, Prevent Orthodontic Relapse, and Modulate Acute Pain During Orthodontic Treatment / A. Farsaii, T. Al-Jewair // J. Evid. Based Dent. Pract. - 2017. - Vol. 17 (3). - P. 262-264.

6. Influence of Electroacupuncture and Laser-Acupuncture on Treating Paresthesia in Patients Submitted to Combined Orthogna- thic Surgery and Genioplasty / R.F. de Oliveira, R.S. Goldman, F.M. Mendes [et al.] // Med. Acupunct. - 2017. - Vol. 29 (5). - P. 290-299.

7. Msallam F.A. Decalcification prevention around orthodontic brackets bonded to bleached enamel using different topical agents / 
F.A. Msallam, M.E. Grawish, A.M. Hafez [et al.] // Prog. Orthod. - 2017. - Vol. 18 (1). - P. 15-17.

8. Yi J. Effectiveness of adjunctive interventions for accelerating orthodontic tooth movement: a systematic review of systematic reviews / J. Yi, J. Xiao, H. Li [et al.] // J. Oral. Rehabil. - 2017. - Vol. 44 (8). - P. 636-654. 